Twenty-four teeth were attached to the plate (six incisors, six molars and premolars in each jaw), it not being thought worth while to restore the small molars at the back of the mouth as they are to a great extent functionless. They were ground down to the proper shape and size from the smallest human incisors made of Ash's porcelain. The cutting edges were protected by thin platinum foil upon which gold solder was fused; this gave an efficient edge and considerably lessened the risk of breakage of the porcelain. The plates were adapted to the mouth exactly as in human dentistry, and they are removed every day to be cleansed.

For the first time or two chloroform had to be used in order that the teeth might be removed or re-inserted, but now the animal submits without any trouble. When inserted for the first time the animal manifested great discomfort for about two hours, but after that he did not offer any objection. Before the teeth were put in the dog weighed $7 \frac{1}{2}$ lbs., and looked very thin and poor; all food taken had to be finely minced or in fluid form; now, however, he eats meat and crunches bones without trouble, and although the teeth have only been in for about a month his weight has increased to 9 lbs. I ounce.

In general health and appearance, too, the dog is most markedly improved.

AN UNUSUALLY LARGE T.ENIA SERRATA.

A complete specimen of the tænia serrata, measuring Io feet 8 inches long and containing 465 segments, was obtained on 16 th November from a greyhound $\operatorname{dog}$ (four years old and weighing 62 lbs.) after the administration of a drachm of tenaline in a drachm of water. The worm was accompanied by two others of the same variety, but the largest of these only measured between 5 and 6 feet.

\title{
NOTES ON SOME NEW THERAPEUTIC APPLICATIONS.
}

By FRED. HobDAY, F.R.C.V.S., Professor of Therapeutics, Royal Veterinary College, London.

\section{TENALINE.}

Tenaline is a new preparation recently prepared by Messrs Willows, Francis, and Butler from the areca nut, with the object of retaining the tæniafuge alkaloids of Arecaine, Arecaidine, and Guvacine, and getting rid as far as possible of the very toxic principle known as Arecoline.

I have now been able to observe its effects and test its efficacy on rather more than sixty cases, the summary of which is as follows :-

Tenaline is certainly of great value as a vermifuge, especially for tapeworms, in the dog and cat. Its effect is rapid, the average time being about fifteen or twenty minutes; the quickest time in which we observed expulsion of tæniæ after its administration was three minutes, one patient being a spaniel suffering from tænia cucumerina, 
and another an Airedale terrier suffering from ascarides. It has the advantage over powdered areca nut of being much easier to administer as its bulk is small, and a purgative is not a necessary adjunct. Its effect on ascarides is also well marked, as they may either become vomited up from the stomach or expelled in the fæces.

Its action on the bowels is to increase secretion and stimulate peristalsis, so that even if no worms be present an animal which has received a full dose passes liquid evacuations. Above all, its general effect seems invariably to be to cause expulsion of the head as well as the segments, thus getting rid of the most troublesome part of the parasite.

With reference to dose, that recommended on the bottle is an allowance of I minim for each pound of body weight, and it is also advised to be administered pure or with the addition of a little water. The latter we found to give the best results, the addition being made of an equal amount or rather more; that the results are better when water is added, especially where small doses of the medicine are prescribed, may be explained by the fact of it being necessary to give a sufficient quantity of fluid to reach and come in direct contact with the worm which is lying in the intestine.

Although one minim for each pound of body weight is usually sufficient, our observations appear to show that this amount can be doubled with absolute safety; in fact, we have in five or six instances allowed 4, and in one case 8 , minims for each pound. The only noticeable effect was vomiting, temporarily increased peristaltic movement of the bowels, accompanied by colic, and the passage of liquid freces; no after results other than those of dulness and slight diarrhoea.

That tenaline is, however, toxic was illustrated by the case of a Maltese terrier, weighing $4 \mathrm{lbs}$, and known to be the host of intestinal parasites. One drachm of pure tenaline was given subcutaneously. In ten minutes the animal became unconscious, respirations became very shallow, and five minutes later the dog was dead.

Post-mortem revealed nothing diagnostic, and the intestines contained living specimens of ascarides and tæniæ.

That it is unsuitable for subcutaneous use was well illustrated by two other instances in which a retriever weighing $35 \mathrm{lbs}$, and a fox terrier weighing 12 lbs., each received a drachm of pure tenaline subcutaneously. Signs of irritation were marked at the seat of injection for about an hour and a half afterwards. During the following week very tender swellings formed, and on the seventh day that on the fox terrier burst, leaving a jagged ulcerating wound which took some time to heal. The retriever was chloroformed and destroyed; the swelling was found on post-mortem to be a large gelatinous mass measuring $5 \times 3$ inches. In the terrier, for about an hour and a half after the injection there were marked rigors, dulness, and salivation.

With reference to the dose which can be administered with safety to other of our patients, a light van horse received on a fasting stomach 2 ounces of tenaline mixed with 4 ounces of water without any noticeable effect. The animal was killed about four hours later, and post-mortem examination revealed a large number of bots in the stomach, also numbers of the strongylus armatus and tænia 
perfoliata in the cæcum, all being alive and apparently uninjured in any way. A donkey received an ounce mixed with 5 ounces of water, whilst another one received 2 ounces mixed with 4 ounces of water; in the latter case the fæces were passed rather more frequently and of a more laxative character than usual, and the animal was rather dull on the succeeding day.

A heifer received an ounce in 6 ounces of water without any effect.

A full-grown sheep received 2 drachms, and another 4 drachms, each in 4 ounces of water, without effect ; whilst on the following day the one which had received 4 drachins received 2 ounces in 6 ounces of water without any noticeable result. A pigeon received to minims made into a pill mass with liquorice, and showed no noticeable symptoms of any kind.

\section{THE USE OF BINIODIDE OF MERCURY AS A SUBSTITUTE FOR POTASSIUM IODIDE.}

The great objection to the use of potassium iodide in veterinary practice, especially for the larger animals, where full and repeated doses have to be employed, is its expense. About two years ago, in the course of conversation, Professor Edgar of Dartford observed that he had been using the biniodide of mercury as a substitute for potassium iodide in the treatment of actinomycosis, and that he found the results to be attended with an equal amount of success. The recipe used consisted of from 2 to 6 grains of biniodide of mercury dissolved in an ounce of water by the aid of from 5 to 10 or 12 grains of potassium iodide. Since then I have always mentioned the matter to my students when lecturing upon the subject, and I have been able to collect a fair number of instances in which it has been tried successfully on cattle suffering from actinomycosis, especially from Messrs Penhale (of Barnstaple), R. W. Hall (at present one of the College tutors), and Harold Masson (of Flaxton, Yorks.); thus confirming the effects observed by Professor Edgar. The only bad effect that I have had reported was that of a cow which temporarily lost all her hair owing to the medicine being given for an unnecessarily long time, without the necessary occasional visit from the veterinary surgeon in charge of the case, to see how matters were progressing. Knowing the value of potassium iodide in the treatment of scirrhous cord, of elephantiasis of the legs following as a sequel to lymphangitis, and of various tumours in the regions of the shoulder and elbow, I determined to give the biniodide of mercury a trial in these cases in horses.

In four cases scirrhous cords were treated with the object of causing them to become small enough in size for operative purposes, each of them being bilateral and much too diffused to give a fair chance of success until reduced by some means. Two of the owners sold their animals after a fortnight as they would not take the trouble of treatment; the third animal could not trot at all when brought to the Clinique, and only walked with difficulty, but after a month's treatment it was able to go to slow trotting work for three days a week, and was then sold and lost sight of.

The fourth case was a cab horse which had been bought when suffering from a large bilateral scirrhous cord; it was brought to the 
Clinique on the IIth of February I 896, and was then absolutely unable to do any work. Two grains of biniodide of mercury, dissolved by the aid of 5 grains of potassium iodide in an ounce of water, were given twice daily in linseed gruel. A week later there was a decided improvement in the way the patient walked, and on 2nd March the horse was sent to slow work.

9th March. The scirrhous cord was perceptibly less, the alterative effect of the medicine was well shown in the animal's improved appearance, and the dose of biniodide was increased to 4 grains twice daily, this being dissolved by 6 grains of potassium iodide.

Treatment was continued until 8th May, the animal now working regularly in a cab, and the cord perceptibly decreasing. On this date the dose of biniodide was increased to 6 grains, Io grains of potassium iodide being necessary to ensure its solution.

On the 22nd the scirrhous cords appeared small enough to permit of removal by the knife and écraseur, and unfortunately this was attempted. The animal died of shock and collapse two hours later.

In the treatment of chronic elephantiasis and of tumours of the shoulder and elbow we have used the biniodide in the Clinique as a substitute for potassium iodide, and have got an equal amount of success, together with the advantage of obtaining the alterative effect of the mercury. Professor Edgar has recently told me that he has also tried it successfully in the horse for the dispersal of glandular enlargements, for capped elbows, and for scirrhous cord; also that he has found it a valuable agent to use as an astringent to the lacteal secretion in mares and cows, and that on this account it must be used with a certain amount of care in milking animals unless it is desired to arrest the secretion.

Summing up the results, it must be admitted (I) That the agent is very much cheaper to use than potassium iodide. (2) That the results which I have been able to collect regarding its value in actinomycosis confirm those which Professor Edgar had already obtained. (3) That the observations which Professor Edgar and myself had been independently making at the same time upon its therapeutic effects as a resolvent, specific, and alterative in certain diseases of the horse appear to demonstrate its value, and to agree in almost every detail. (4) We have each found that, as is frequently the case with potassium iodide, failure to continue with the medicine for a sufficiently long time may cause a relapse, the tumours again enlarging.

\section{ANKYLOSIS OF THE FETLOCK JOINT,}

By E. E. Martin, Vet.-Lieut., A.V.D., Barrackpore, India.

A well-marked case of this affection came under my notice a short time ago, and as I had an opportunity of photographing the legs during life and the bones after death, I thought a short account of it might interest the readers of this Journal.

The case was a country-bred chestnut pony mare, aged, height about $\mathrm{I} 3$ hands 3 inches. The owner, an artillery officer in this station, had purchased her about a year previous to the time I saw 